\title{
Determination of dip direction for the 2007 Chuetsu-oki earthquake from relocation of aftershocks using arrival times determined by cross-correlation
}

\author{
Jim Mori \\ Disaster Prevention Research Institute, Kyoto University, Japan \\ (Received October 1, 2007; Revised April 13, 2008; Accepted April 29, 2008; Online published November 18, 2008)
}

\begin{abstract}
Waveform correlations were used to redetermine $P$ arrival times at 31 stations for a selected set of 321 aftershocks of the 2007 Chuetsu-oki earthquake. These data were used with several different relocation techniques, 1-D velocity structure, 3-D velocity structure using SIMULPS12, 1-D velocity structure using hypoDD, and 3-D velocity structure using tomoDD. The results from all of these methods show a consistent southeast dipping trend for the entire aftershock sequence. The same pattern is also seen for the time period before the largest aftershock. These results indicate that the mainshock fault dips to the southeast.
\end{abstract}

Key words: Aftershocks, Chuetsu-oki earthquake, fault plane.

\section{Introduction}

The 2007 Chuetsu-oki earthquake ( $\left.M_{\mathrm{w}} 6.6\right)$ occurred off the northwest coast of central Japan at 01:13 (UTC) on July 16, 2007. The focal mechanism showed a thrust fault striking in a northeast direction. As is common practice, the aftershock distribution is used to determine the fault plane. Although most aftershocks probably do not occur directly on the fault plane of the mainshock (e.g. Liu et al., 2003), they are usually located close enough so that at the scale of several kilometers the spatial pattern should be a good representation of the fault plane of the mainshock (and possibly large aftershocks). For this earthquake, there have been different interpretations of the aftershock distribution in determining the orientation of the mainshock fault. An early report of the Earthquake Research Committee indicated a southeast dipping fault from routine aftershock locations by the Japan Meteorological Agency (JMA) and the National Institute for Earth Science and Disaster Prevention (NIED), but this was later amended to say that it was difficult to determine the fault plane (http://www.jishin.go.jp/main/index-e.html). Relocations of aftershocks by Hirata et al. (2007) proposed a northwest dipping fault for the mainshock and a southeast dipping fault for the largest aftershock. This volume also contains other aftershock relocations papers that suggest a more complex pattern of conjugate faulting (Kato et al., 2008; Yukutake et al., 2008).

In this paper, several hypocenter relocation methods are used with a carefully selected set of arrival times determined from cross correlations of waveforms, to investigate the spatial distribution of aftershocks and the orientation of the fault plane of the mainshock. The main purpose is to try

Copyright (c) The Society of Geomagnetism and Earth, Planetary and Space Sciences (SGEPSS); The Seismological Society of Japan; The Volcanological Society of Japan; The Geodetic Society of Japan; The Japanese Society for Planetary Sciences; TERRAPUB to determine if the fault dips toward the northwest, southeast, or some combination of the two directions. The aftershocks are relocated using several different algorithms to show that we can obtain consistent results for the seismicity pattern, which are not dependent on the location method.

\section{Data}

A consistent data set of $P$ arrival times was used by examining all available events in the online database of $\mathrm{Hi}$ Net operated by NIED, in the size range of $M_{\mathrm{j}} 2.2$ to $M_{\mathrm{j}} 3.0$ from July 16 to July 31 , in a box bounded by $37.3^{\circ}$ to $37.7^{\circ} \mathrm{N}$ and $138.4^{\circ}$ to $138.8^{\circ} \mathrm{E}$. The lower magnitude range was chosen so that there was reasonable signal to noise at all of the chosen stations. Events larger than $M_{\mathrm{j}} 3.0$ were not used because the source effects begin to significantly affect the waveforms used in the cross correlations. Waveform data were used from 31 stations shown in Fig. 1, which were selected to maximize the azimuthal coverage. Of the 327 available events listed on the webpage, 320 events that had clear arrivals at 6 or more stations were used for the study.

\section{Arrival Determination Using Cross Correlation of Waveforms}

In order to obtain improved relative determinations of $P$ arrival times, a cross correlation procedure with a representative waveform is used. The waveforms for all events recorded at a single stations were aligned on the arrival time determined by JMA. A clear representative arrival was chosen as a model and cross-correlations were done with each waveform to determine the best lag that matched the model waveform.

The data were low-pass filtered at $5 \mathrm{~Hz}$, so the arrival times are based on relatively low-frequency characteristics in the waveforms, which are sampled at $100 \mathrm{~Hz}$. A time window of $0.5 \mathrm{sec}$ from the JMA arrival time was used. 

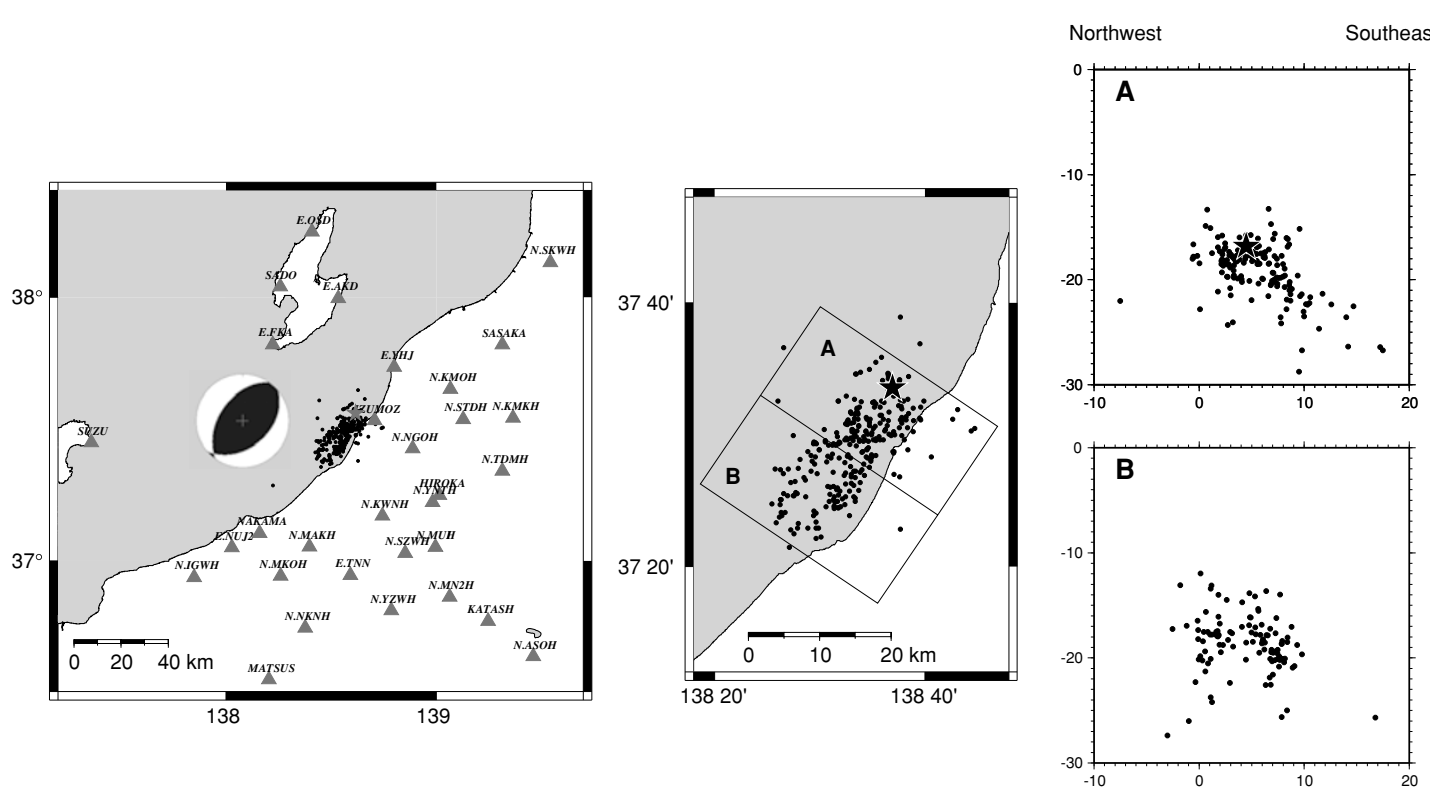

Fig. 1. 31 stations used in this study are shown in the left map. The distribution of aftershocks used in this study as determined by JMA, is shown in the middle map and cross sections on right. Cross sections are shown for the two regions (A and B) shown by boxes on the middle map.

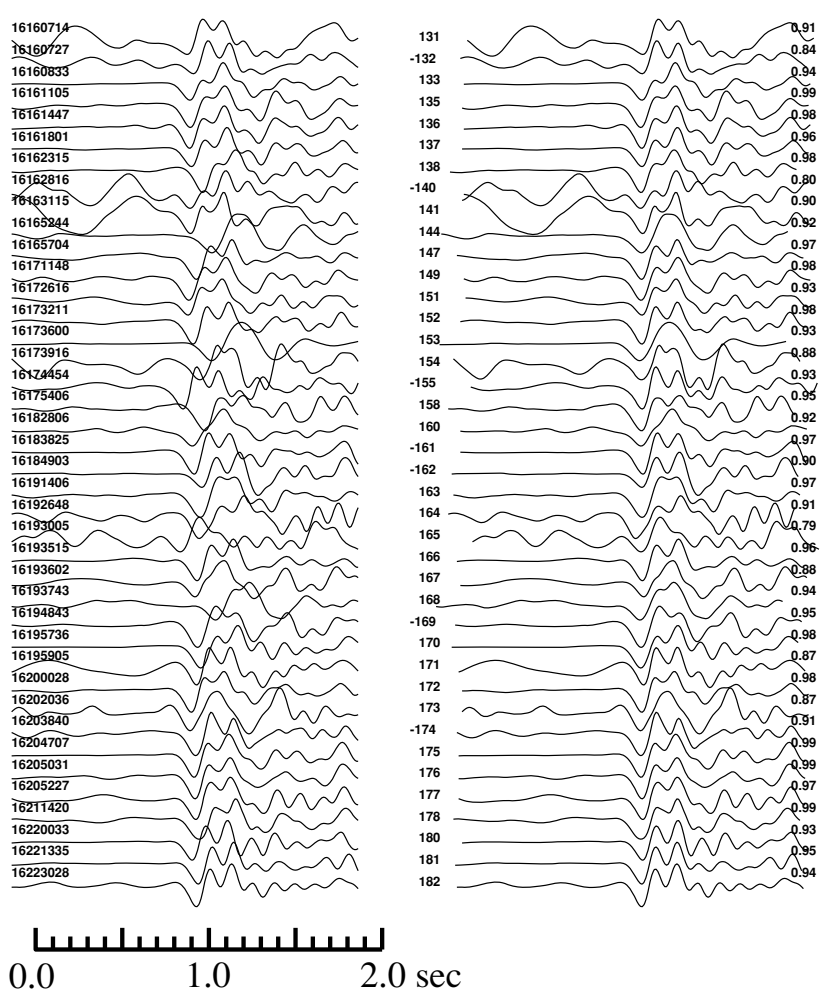

Fig. 2. Example of cross correlation of waveforms to determine arrival times at station NGOH. Left column is original data aligned on the $P$ arrival determined by JMA. Right column is data aligned by cross correlation. A minus number in the middle column indicates the polarity was reversed to match the model waveform. Numbers in column on the right are the correlation coefficients.

All of the waveforms were visually inspected, so that polarity differences (due to differences in focal mechanism and source-receiver geometry) were reversed to match the model waveform. Less correlated waveforms (correlation coefficient less than about 0.8 ) were discarded. Figure 2 shows an example of waveforms at one station, NGOH, before and after alignment by the cross correlation process.

Since the source durations of these earthquakes $\left(M_{\mathrm{j}} 2.2\right.$ to $M_{\mathrm{j}} 3.0$ ) are typically 0.03 to $0.1 \mathrm{sec}$, the shapes of the waveforms in Fig. 2 are dominated by the propagation effects. Furthermore, the similarity of the waveforms indicates that the local site effect has the largest influence on the shape of the waveforms.

More extensive methods using waveform correlations between many pairs of waveforms (e.g. Got et al., 1994; Waldhauser and Ellsworth, 2000; Shearer et al., 2005) have been developed for earthquake locations. These methods were not used here in order to clearly separate the effects of the arrival time determination and the earthquake location algorithm.

\section{Results}

The results of the various methods of hypocenter determinations are shown in Fig. 3. Only cross sections are shown because the epicentral distribution does not differ greatly from that shown in Fig. 1. The cross sections are oriented in a N56W-S56E direction, which was chosen as a representative value from the fault strike in the moment tensor solutions determined by USGS and NIED. For the cross sections, the aftershock area is divided into two regions (A and B in Fig. 1), because there seems to be significant difference in the dip of the aftershock trend, with the northern region showing a steeper dip.

Figure 3(a) shows the results using a 1-D velocity structure derived from Shibutani et al. (2005). The velocity structure is shown in Table 1. The aftershocks moved to shallower depths compared to the original JMA locations (Fig. 1). The shallower distribution seems reasonable since it is consistent with the centroid moment tensor depth of $8 \mathrm{~km}$, determined by NIED using regional waveform data. 
a) 1-D
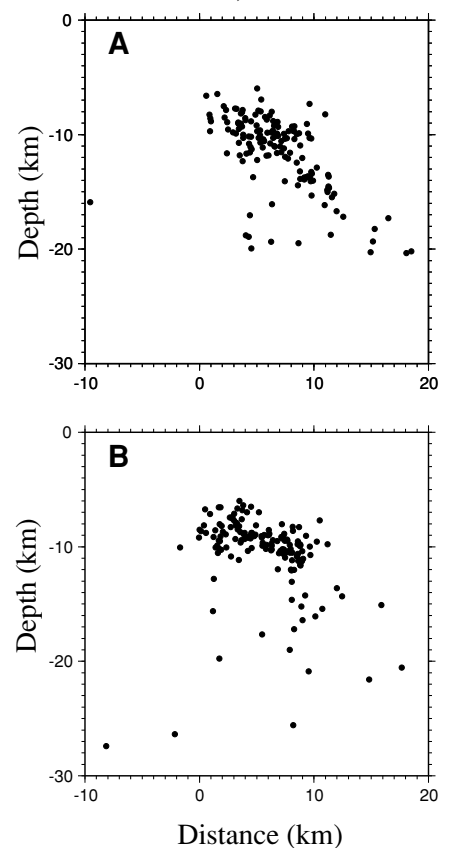

b) 3-D

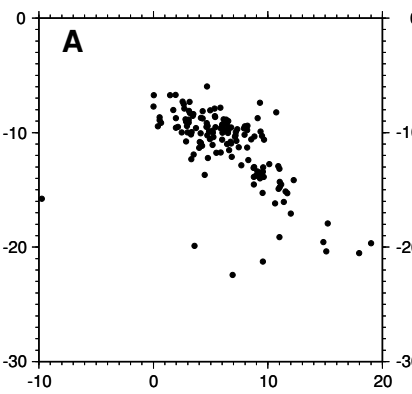

c) hypoDD
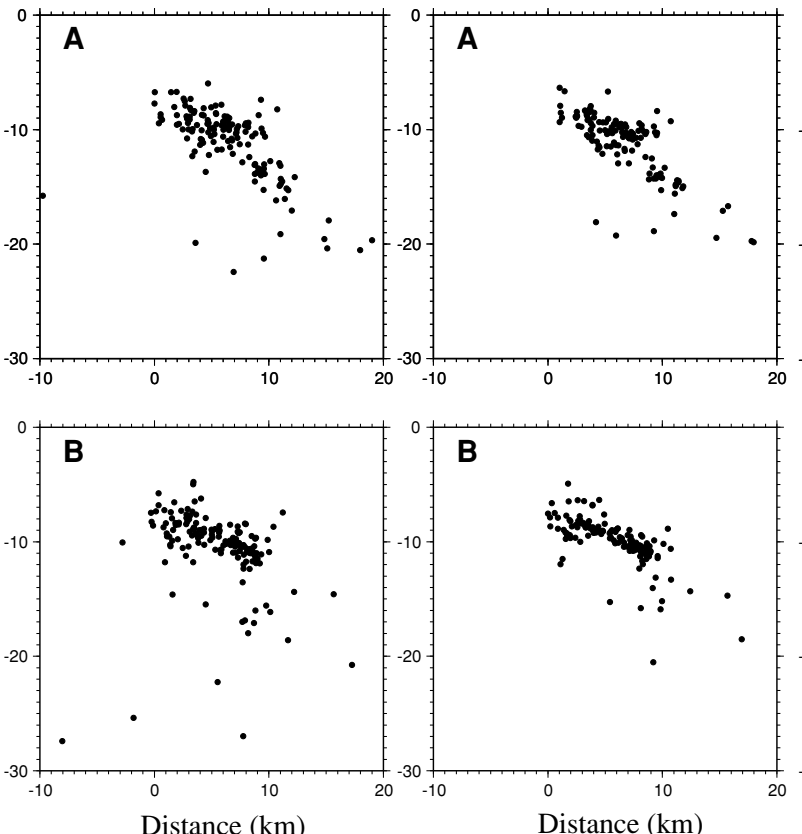

d) tomoDD

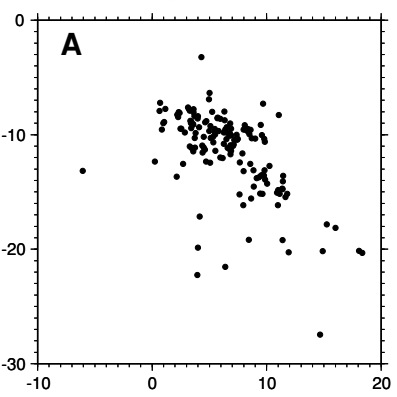

Fig. 3. Relocated hypocenters using (a) 1-D velocity model (b) 3-D velocity model and SIMULPS12 program (c) hypoDD program (d) tomoDD program.

Table 1. 1-D velocity model.

\begin{tabular}{cc}
\hline Depth $(\mathrm{km})$ & $P$ velocity $(\mathrm{km} / \mathrm{sec})$ \\
\hline 0 & 5.0 \\
3 & 5.0 \\
5 & 5.3 \\
7 & 6.0 \\
17 & 7.0 \\
25 & 7.5 \\
\hline
\end{tabular}

The aftershock hypocenters show a fairly consistent southeast dipping trend. The largest changes from the original JMA locations are the relatively shallower depths for events on the western side of the southern region (B).

Figure 3(b) shows the results using the program SIMULPS12 (Eberhart-Phillips, 1993; Evans et al., 1994). The 1-D velocity structure shown in Table 1 was used as the input structure. The program simultaneously computes hypocenters and adjustments to a $3-\mathrm{D}$ velocity structure. Similar to the 1-D results, there appears to be a consistent southeast dipping trend for the aftershocks.

Figure 3(c) shows the result using the program hypoDD (Waldhauser and Ellsworth, 2000; Waldhauser, 2001) which uses a double-difference algorithm. Among the various setup parameters, the value of damping can significantly change the shape of the hypocenter distribution and controls the degree to which the locations become clustered. A damping value of 30 was used and lower values give a more horizontally shaped distribution. The starting velocity model was the 1-D model shown in Table 1 . If a velocity model more similar to the JMA model is used, the shape of the aftershock distribution is similar, but located about 5 to $7 \mathrm{~km}$ deeper.
Figure 3(d) shows the results using the program tomoDD (Zhang and Thurber, 2003) which combines the doubledifference algorithm with determination of a 3-D velocity structure. The input velocity model is given in Table 1 . The results are shown for a damping factor of 30, which was chosen as a reasonable value for the trade-off between the error and damping effect. A clear southeast dip of the aftershocks can be seen. Similar to SIMULPS12, this program also produces a three-dimensional velocity structure. The velocity structures obtained here and from SIMULPS12, both show the faster velocities of the ocean region compared to the Honshu coastal area at depths of about 15 to $25 \mathrm{~km}$.

\section{Early Aftershocks}

It has been suggested by Hirata et al. (2007) that the southeast dipping trend is due to secondary aftershocks of the largest aftershock $\left(M_{\mathrm{j}} 5.8\right)$ at 6:37 (UTC) on July 16 . Figure 4 shows the relocated hypocenters that occurred during the first 5 hours before the largest aftershock. All the events for the entire region are shown on single cross sections. Because of the many aftershocks which complicate the waveforms in the first few hours, there are fewer well correlated arrival times, so the locations are more uncertain. However, for this time period there still seems to be a southeast dipping trend for all of the relocation methods.

\section{Depth Uncertainties}

It is important to consider the uncertainties in the depth determinations when interpreting the aftershock patterns in Fig. 3. The average errors in depth location given by the programs are very small $(1.79,1.18,0.20,0.17 \mathrm{~km}$ for $1-\mathrm{D}$, $3-\mathrm{D}$, hypoDD and tomoDD, respectively) and calculated assuming random errors in the arrival time. Depth errors can 
a) 1-D

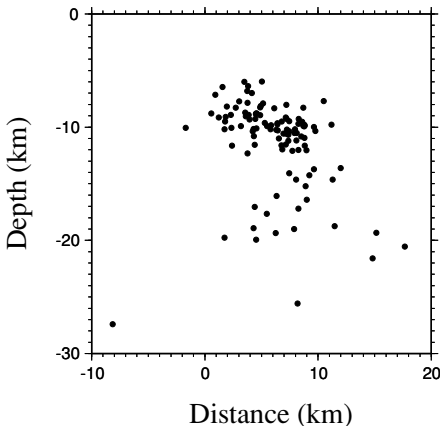

b) 3-D

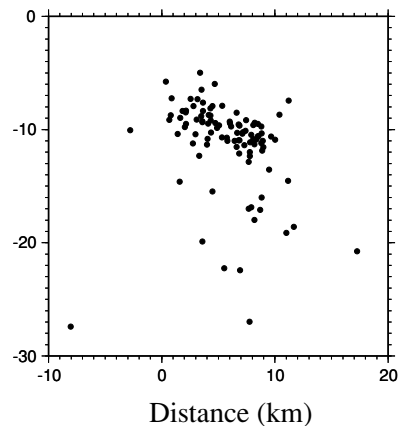

c) hypoDD

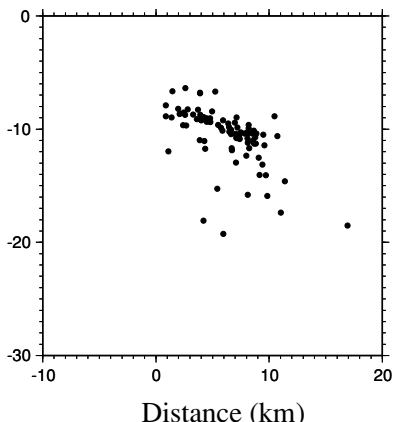

d) tomoDD

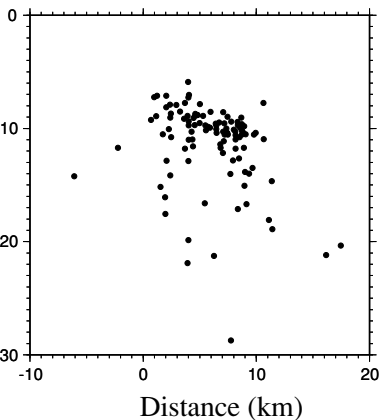

Fig. 4. Relocated hypocenters for the time before the largest aftershock at 06:37, using (a) 1-D velocity model (b) 3-D velocity model and SIMULPS12 program (c) hypoDD program (d) tomoDD program.

lead to errors in calculated take-off angles which can affect the obtained seismicity pattern. These uncertainties are unrealistically small, even in considering relative locations. To obtain more appropriate error estimates, it is necessary to evaluate the systematic errors, such as from uncertainties in the velocity structures, systematic differences in the way arrival times are picked, and parameter choices that control the clustering of events in the double-difference algorithms. This is more difficult and appropriate methods need to be used (Got et al., 1994). Although it is difficult to assess the uncertainty of individual events, the overall depth distribution determined in this study from the onshore permanent network, is similar to the results obtained for a later time period using ocean-bottom seismomters (OBS) by Shinohara et al. (2008). In general, the overall distribution of the aftershocks showing a single southeastward dipping plane, which was obtained that OBS study is similar to the results of this paper.

In additional to the uncertainties in depth, there is an uncertainty in the relative depth locations that can affect the dip of the seismicity pattern. Dips of the seismicity pattern in the northern region are close to about $45^{\circ}$ which is consistent with the value from the NIED moment tensor solution $\left(42^{\circ}\right)$. In the southern region the dip of the seismicity seems to be considerably shallower, particularly for the doubledifference methods. It is not clear if this is a real feature or due to the methodology when the station coverage is poorer.

\section{Conclusions}

Using $P$-arrival times determined by cross-correlation of waveforms from a consistent set of selected earthquakes ( $M_{\mathrm{j}} 2.2$ to $M_{\mathrm{j}} 3.0$ ), relocations of hypocenters using several different methods show a consistent southeast dip for the entire aftershock distribution in space and time, which is generally consistent with the southeast dipping nodal plane of the focal mechanism. These results show that using only the permanent Hi-Net data with carefully determined arrival times, the main orientation of the mainshock fault can be determined and is shown to dip to the southeast.

Acknowledgments. We thank the National Institute for Earth Science and Disaster Prevention for the use of the Hi-Net data and the Japanese Meteorological Agency for the hypocenter and phase catalogs. Helpful comments were provided by D. EberthartPhillips and J. Got.

\section{References}

Eberthart-Phillips, D., Local earthquake tomography: Earthquake source regions, in Seismic Tomography; Theory and Practice, edited by H. M. Iyer and K. Hirahara, 842 pp, Chapman and Hall, London, 1993.

Evans, J., D. Eberhart-Phillips, and C. H. Thurber, User's manual for SIMULPS 12 for imaging $v_{p}$ and $v_{p} / v_{s}$ : A derivative of the 'Thurber' tomographic inversion SIMUL3 for local earthquakes, USGS Open-File Report, 94-431, 1994.

Got, J.-L., J. Frechet, and F. W. Klein, Deep fault plane geometry inferred from multiplet relative relocation beneath the south flank of Kilauea, $J$. Geophys. Res., 99, 15,375-15,386, 1994.

Hirata, N., H. Sato, S. Sakai, and A. Kato, The earthquake source fault of the 2007 Niigata-ken Chuetsu-Oki earthquake: The relationship with the seismogenic Nagaoka Plain Seien Fault Zone, Kagaku, 77, 930-934, 2007 (in Japanese).

Kato, A., S. Sakai, E. Kurashimo, T. Igarashi, T. Iidaka, N. Hirata, T. Iwasaki, T. Kanazawa, and Group for the aftershock observations of the 2007 Niigataken Chuetsu-oki Earthquake, Imaging heterogeneous velocity structures and complex aftershock distributions in the source region of the 2007 Niigataken Chuetsu-oki Earthquake by a dense seismic observation, Earth Planets Space, 60, this issue, 1111-1116, 2008.

Liu, J., K. Sieh, and E. Hauksson, A structural interpretation of the aftershock 'Cloud' of the $1992 M_{\mathrm{w}} 7.3$ Landers earthquake, Bull. Seismol. Soc. Am., 93, 1333-1344, 2003.

Shearer, P., E. Hauksson, and G. Lin, Southern California hypocenter relocation with waveform cross-correlation, part 2: Results using sourcespecific station terms and cluster analysis, Bull. Seismol. Soc. Am., 95, 904-915, 2005.

Shibutani, T., H. Katao, and Group for the dense aftershock observations of the 2000 Western Tottori Earthquake, High resolution 3-D velocity structure in the source region of the 2000 Western Tottori Earthquake in southwestern Honshu, Japan using very dense aftershock observations, Earth Planets Space, 57, 825-838, 2005

Shinohara, M., T. Kanazawa, T. Yamada, K. Nakahigashi, S. Sakai, R. Hino, Y. Murai, A. Yamazaki, K. Obana, Y. Ito, K. Iwakiri, R. Miura, Y. Machida, K. Mochizuki, K. Uehira, M. Tahara, A. Kuwano, S. Amamiya, S. Kodaira, T. Takanami, Y. Kaneda, and T. Iwasaki, Precise aftershock distribution of the 2007 Chuetsu-oki Earthquake obtained by using an ocean bottom seismometer network, Earth Planets Space, 60, this issue, 1121-1126, 2008.

Waldhauser, F., hypoDD: A program to compute double-difference hypocenter locations, USGS Open-File Report, 01-113, 2001.

Waldhauser, F. and W. L. Ellsworth, A double-difference earthquake location algorithm: Method and application to the Northern Hayward fault, Bull. Seismol. Soc. Am., 90, 1353-1368, 2000.

Yukutake, Y., T. Takeda, and K. Obara, Well-resolved hypocenter distribution using the double-difference relocation method in the region of the 2007 Chuetsu-oki Earthquake, Earth Planets Space, 60, this issue, 1105-1109, 2008.

Zhang, H. and C. H. Thurber, Double-difference tomography: The method and its application to the Hayward fault, California, Bull Seismol. Soc. Am., 93, 1875-1889, 2003.

J. Mori (e-mail: mori@eqh.dpri.kyoto-u.ac.jp) 